\title{
3D Numerical Study on Laminar Forced Convection in V-Baffled Square Channel
}

\author{
${ }^{1}$ Amnart Boonloi and ${ }^{2}$ Withada Jedsadaratanachai \\ ${ }^{1}$ Department of Mechanical Engineering Technology, College of Industrial Technology, \\ King Mongkut's University of Technology North Bangkok, Bangkok 10800, Thailand \\ ${ }^{2}$ Department of Mechanical Engineering, Faculty of Engineering, \\ King Mongkut's Institute of Technology Ladkrabang, Bangkok 10520, Thailand
}

Received 2013-02-09, Revised 2013-02-09; Accepted 2013-09-03

\begin{abstract}
The article presents a mathematical study of fully developed periodic laminar flow visualization and heat transfer characteristics in an isothermal wall square-channel fitted with $\mathrm{V}$-shaped baffles on one wall. The computations based on the finite volume method together with the SIMPLE algorithm have been performed. The investigation covers a range of $\mathrm{Re}$ based on the hydraulic diameter of the channel, $\mathrm{Re}=100-1200$. To create a pair of main streamwise vortex flows through the tested section, the V-baffles with the attack angle of $30^{\circ}$ with the main flow direction are mounted in tandem and pointing downstream on the lower channel wall only. Effects of different baffle heights and pitches on heat transfer and pressure drop in the channel are examined and the results obtained are compared with smooth channel with no baffle. The numerical result shows that the presence of the V-baffle yields a significant heat transfer enhancement compared with the smooth channel. It is visible that the main vortex flows, a pair of streamwise twisted vortex (P-vortex) can induce impingement flows on the walls leading to a drastic increase in heat transfer rate over the channel. In addition, the increase in the baffle height leads to the rise in the heat transfer and pressure loss while that in the baffle pitch provides the opposite trend. The predicted results expose that the maximum thermal enhancement factors for the V-baffles with $\mathrm{BR}=0.3,0.3$ and 0.4 ; and $\mathrm{PR}=1,1.5$ and 2 are, respectively, about $2.44,2.29$ and 2.37 at higher Re.
\end{abstract}

Keywords: Periodic Flow, Square Channel, Laminar Flow, Heat Transfer, V-Shaped Baffle

\section{INTRODUCTION}

The use of ribs/baffles (Promvonge et al., 2012a; 2012b; Sriromreun et al., 2012) in duct or channel heat exchanger is one of the commonly used passive heat transfer enhancement strategies in single-phase internal flows. Repeatedly positioned ribs/baffles in the channels periodically can interrupt hydrodynamic and thermal boundary layers resulting in a greater increase of the heat transfer rate.

Many investigators had been studied on V-shaped turbulators or vortex generators. Peng et al. (2011) investigated on both experimentally and numerically for convection heat transfer in channels with different types of ribs. The results indicated that the $45^{\circ} \mathrm{V}$ shaped continuous ribs have the highest thermal performance. Karwa and Chitoshiya (2013) experimentally studied of thermo-hydraulic performance of a solar air heater with $60^{\circ} \mathrm{V}$-down discrete rib roughness on the air flow side of the absorber plate. They found that the enhancement in the thermal efficiency due to the roughness on the absorber plate is found to be $12.5-20 \%$ depending on the air flow rate. In addition, influences of angled King Mongkut's University of Technology North Bangkok, Bangkok 10800, Thailand 
baffles (or thin ribs) placed on two opposite walls of a square channel on heat transfer and flow characteristics were examined numerically (Promvonge and Kwankaomeng, 2010; Promvonge et al., 2010a; 2010b). The investigations revealed that the streamwise vortex flows caused by the angled baffles exist and assist to induce impingement jets on the channel walls leading to a drastic increase in the heat transfer rate.

Although numerous studies on rib and baffle roughened surfaces have been reported in the literature, there has rarely been published on how the fluid flow and heat transfer behavior in the V-baffled channels are influenced by the spacing and height of the baffles, especially for numerical works. Experimental measurements are often limited by the confined space and measurement points available. Therefore, the main aim of the present study is to investigate the fluid flow and heat transfer characteristics in the square channel with different baffle height and spacing intensities using a computer simulation. The numerical computations for three dimensional laminar periodic channel flows over a $30^{\circ}$ $\mathrm{V}$-downstream baffle mounted only on the lower square channel wall are conducted.

\section{MATERIALS AND METHODS}

\subsection{Geometry of Baffled Channel and Arrangement}

Figure 1 shows the V-shaped baffles placed repeatedly on the lower wall of a square channel including the computational domain of a periodic flow module employed in the present work. The V-baffles are arranged by letting the V-tip point to downstream flow (V-downstream baffle). The flow under consideration is expected to attain a periodic flow condition in which the velocity field and thermal profile repeat itself from one module to another. The concept of periodically fully developed flow and its solution procedure has been described by (Promvonge et al., 2012b). In the channel module, the air enters at an inlet temperature, $\mathrm{T}_{\text {in }}$ and flows over a baffle where $\mathrm{b}$ is the baffle height, $\mathrm{H}$ set to $0.05 \mathrm{~m}$, is the channel height and $\mathrm{b} / \mathrm{H}$ is known as the blockage ratio, BR. The distance between the baffles is set to $\mathrm{L}$ in which $\mathrm{L} / \mathrm{H}$ is defined as the pitch ratio, $\mathrm{PR}$. To investigate an interaction effect of the baffles with an attack angle, $\alpha=30^{\circ}$ with the flow direction, BR and PR values are varied in a range of $\mathrm{BR}=0.1-0.5$ and $\mathrm{PR}=$ 1.0-2.0 in the present study.

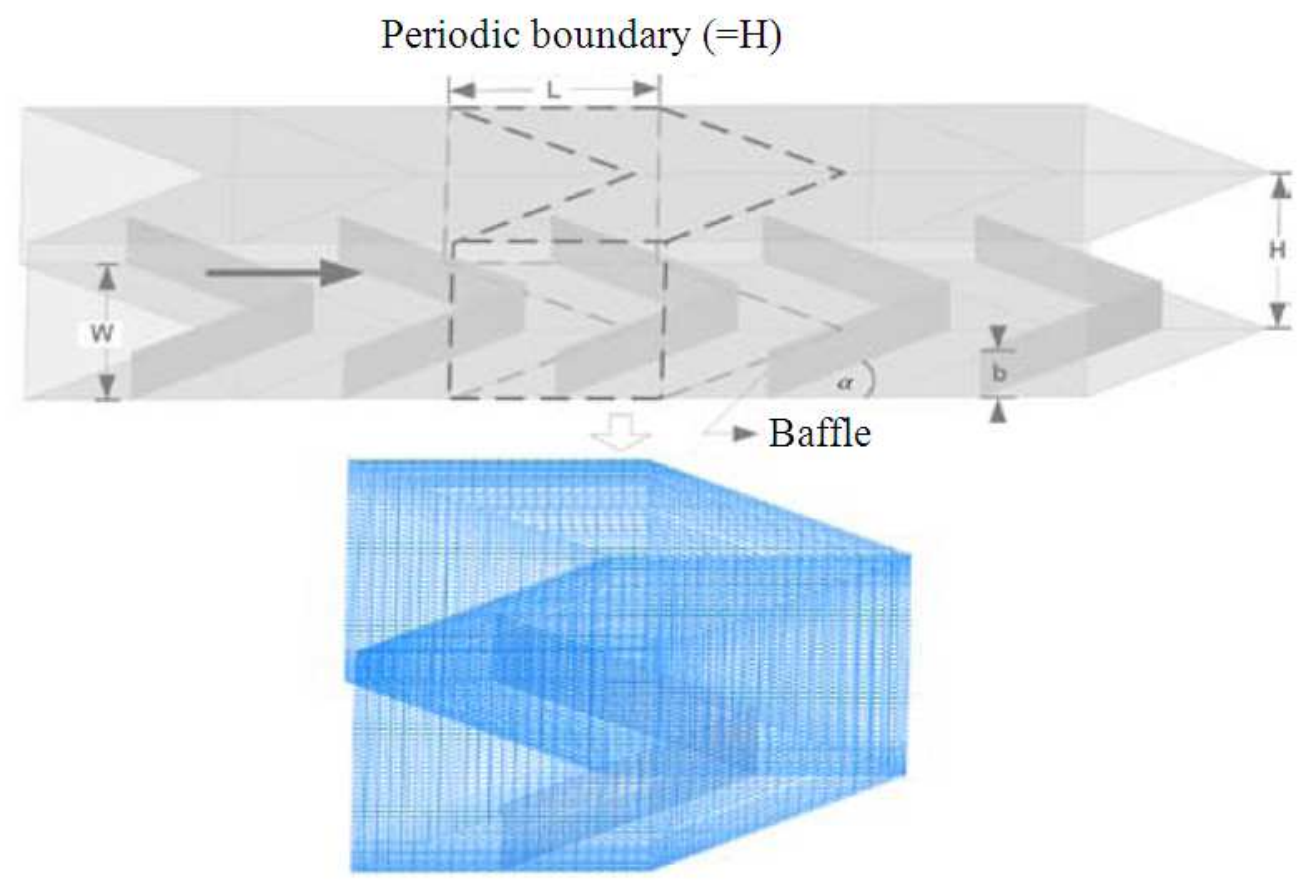

Fig. 1. Channel geometry and computational domain of periodic flow for V-shaped baffle 


\subsection{Mathematical Modeling}

Promvonge and Kwankaomen (2010) and Promvonge et al. (2010a; 2010b; 2012b), the numerical model for fluid flow and heat transfer in a channel is developed under the following assumptions:

- Three-dimensional, steady, laminar and incompressible air flow

- The flow and heat transfer in the channel is fully developed periodic

- Constant air properties

- Body forces and viscous dissipation are ignored

- Negligible radiation heat transfer

The present problem is three-dimensional, laminar and steady. The relevant equations are the Navier-Stokes equations and energy equation. The equations in the tensor notation form are as follows.

Continuity Equation 1:

$$
\frac{\partial}{\partial \mathrm{x}_{\mathrm{i}}}\left(\rho \mathrm{u}_{\mathrm{i}}\right)=0
$$

Momentum Equation 2:

$$
\frac{\partial\left(\rho u_{i} u_{j}\right)}{\partial x_{j}}=-\frac{\partial p}{\partial x_{i}}+\frac{\partial}{\partial x_{j}}\left[\mu\left(\frac{\partial u_{i}}{\partial x_{j}}+\frac{\partial u_{j}}{\partial x_{i}}\right)\right]
$$

Energy Equation 3:

$$
\frac{\partial}{\partial \mathrm{x}_{\mathrm{i}}}\left(\rho \mathrm{u}_{\mathrm{i}} \mathrm{T}\right)=\frac{\partial}{\partial \mathrm{x}_{\mathrm{j}}}\left(\Gamma \frac{\partial \mathrm{T}}{\partial \mathrm{x}_{\mathrm{j}}}\right)
$$

where, $\Gamma$ is the thermal diffusivity and is given by Equation 4:

$$
\Gamma=\frac{\mu}{\operatorname{Pr}}
$$

Apart from the energy equation discretized by the QUICK scheme, the governing equations were discretized by the power law scheme, decoupling with the SIMPLE algorithm and solved using a finite volume approach (Versteeg and Malalasekera, 2007). The solutions were considered to be converged when the normalized residual values were less than $10^{-6}$ for all variables except for the energy equation set to be converged at less than $10^{-9}$.

Four parameters of interest in the present work are the Reynolds number, friction factor, Nusselt number and thermal enhancement factor (Promvonge et al., 2012b).

\subsection{Boundary Conditions}

Promvonge and Kwankaomen (2010) and Promvonge et al. (2010a; 2010b; 2012b), periodic boundaries are used for the inlet and outlet of the flow domain. The constant mass flow rate of air with $300 \mathrm{~K}$ is assumed in the flow direction rather than constant pressure drop due to periodic flow and thermal profile conditions. The inlet and outlet profiles for the velocities and heat transfer must be identical. The physical properties of the air have been assumed to remain constant at average bulk temperature. Impermeable boundary and no-slip wall conditions have been implemented over the channel walls as well as the baffle. The constant temperature of all channel walls is maintained at $310 \mathrm{~K}$ while the V-baffle is set to an adiabatic wall condition.

\section{RESULTS AND DISCUSSION}

\subsection{Accuracy Validation and Grid system}

For validating the accuracy of numerical solutions, the computations of fully developed laminar forced convection in a square channel with no baffle have been carried out to compare with the exact solutions as shown in Fig. 2a and b, respectively. The present numerical smooth channel result is found to be in excellent agreement with the exact solutions obtained from the open literature (Incropera et al., 2007) for both the Nusselt number and the friction factor, less than $\pm 0.5 \%$ deviation.

Grid independent tests have been performed by using three different grid systems with 85,600, 125,500 and 245,600 cells to calculate the flow and thermal fields in the baffled channel. The test was conducted for the baffled channel with $\mathrm{BR}=0.30, \mathrm{PR}=1$ and $\mathrm{Re}=800$. It is found that the difference in heat transfer and friction coefficients among the grids used is less than $1.3 \%$. Accordingly, the grid system of 85,600 cells is employed to perform the current calculations.

\subsection{Flow Structure}

The flow and vortex coherent structure in a square channel fitted with $\mathrm{V}$-shaped baffles on the lower wall only can be displayed by considering the streamline planes as depicted in Fig. 3. Here the streamline planes of the V-baffle modules by connecting the computed modules in series as shown in Fig. 3a, b and c are presented at $\mathrm{Re}=1000$ and $\mathrm{BR}=0.3$ for (a) $\mathrm{PR}=1$, (b) $\mathrm{PR}=1.5$ and (c) $\mathrm{PR}=2$, respectively. 
Amnart Boonloi and Withada Jedsadaratanachai / American Journal of Applied Sciences 10 (10): 1287-1297, 2013

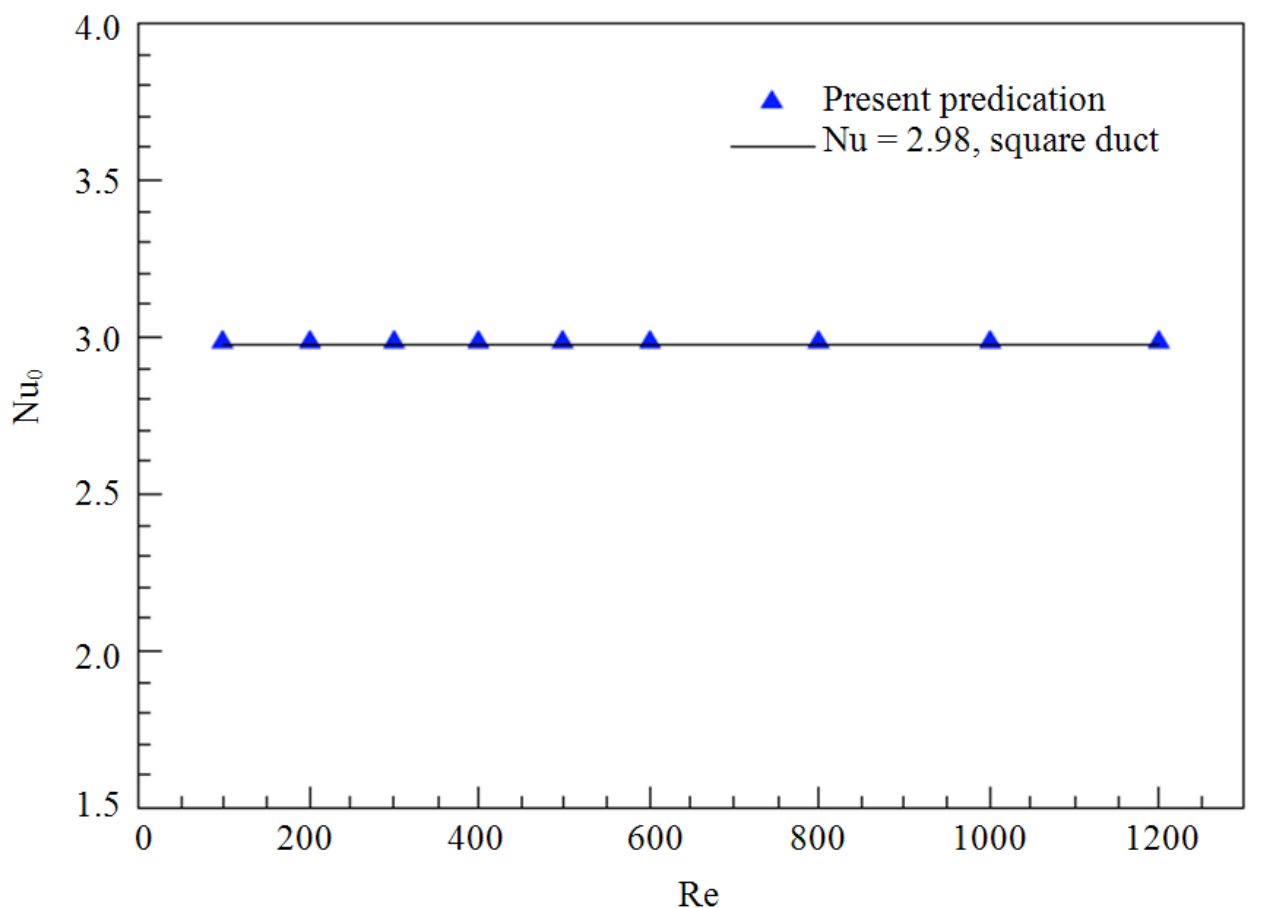

(a)

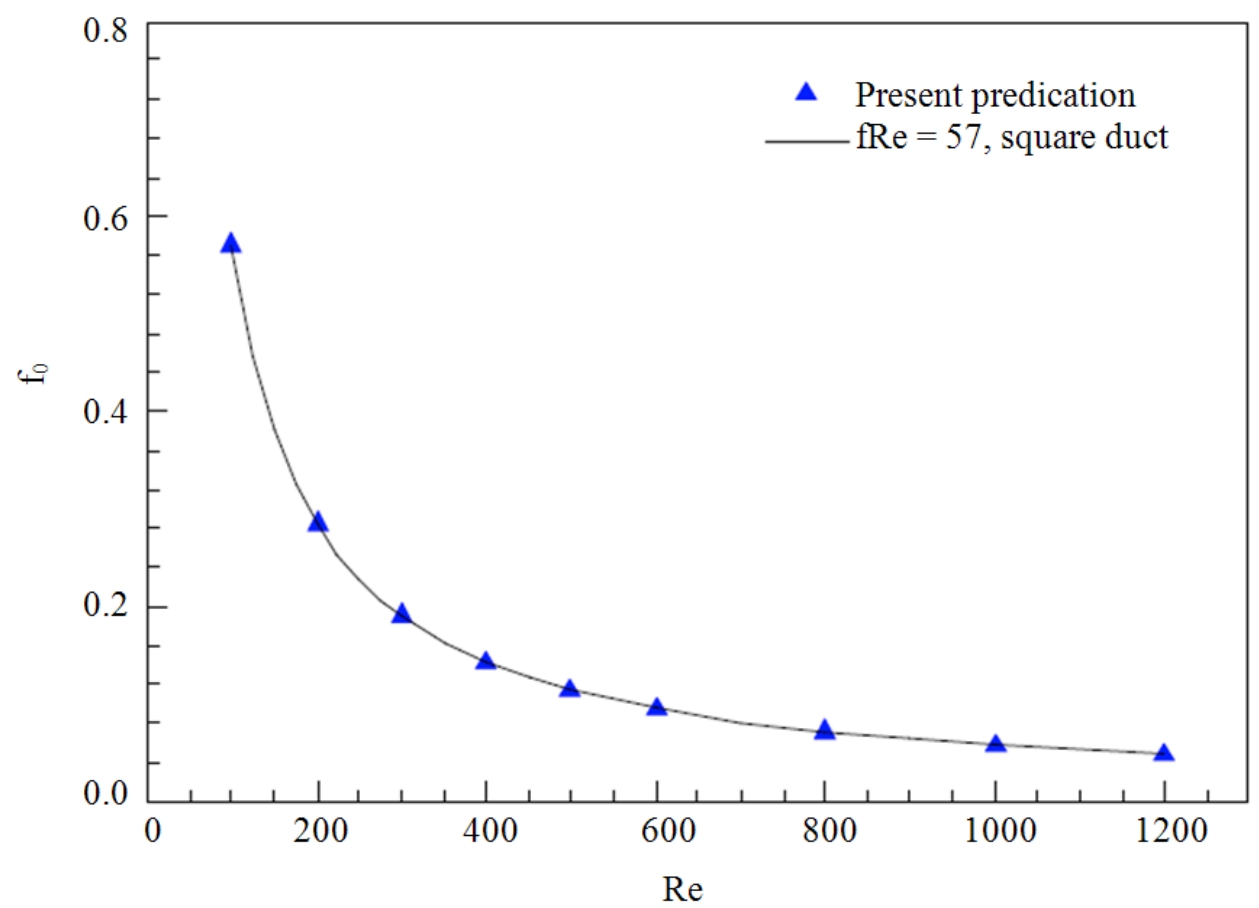

(b)

Fig. 2. Validation of (a) Nusselt number and (b) friction factor for smooth channel 


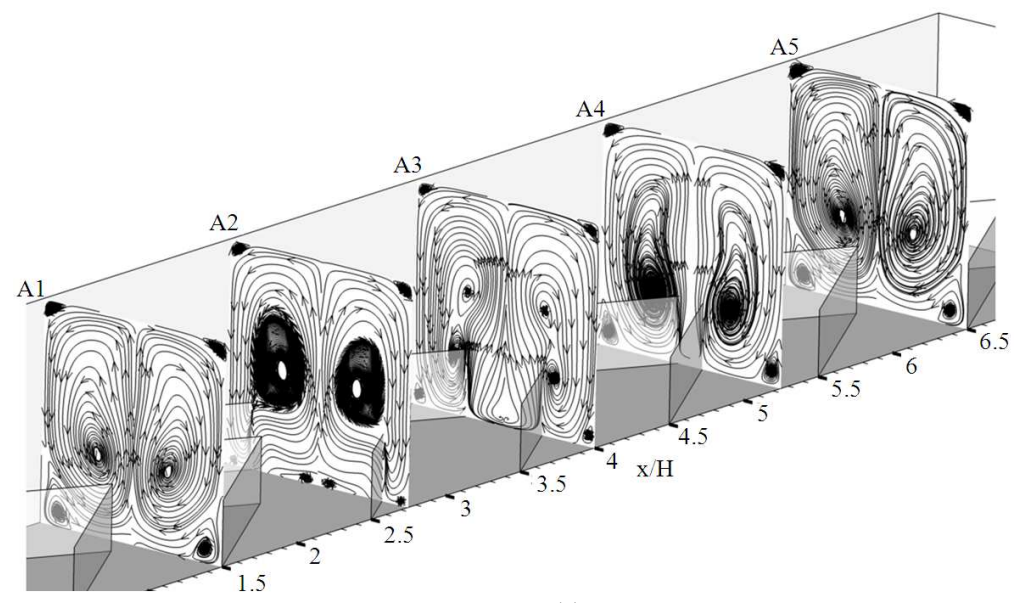

(a)

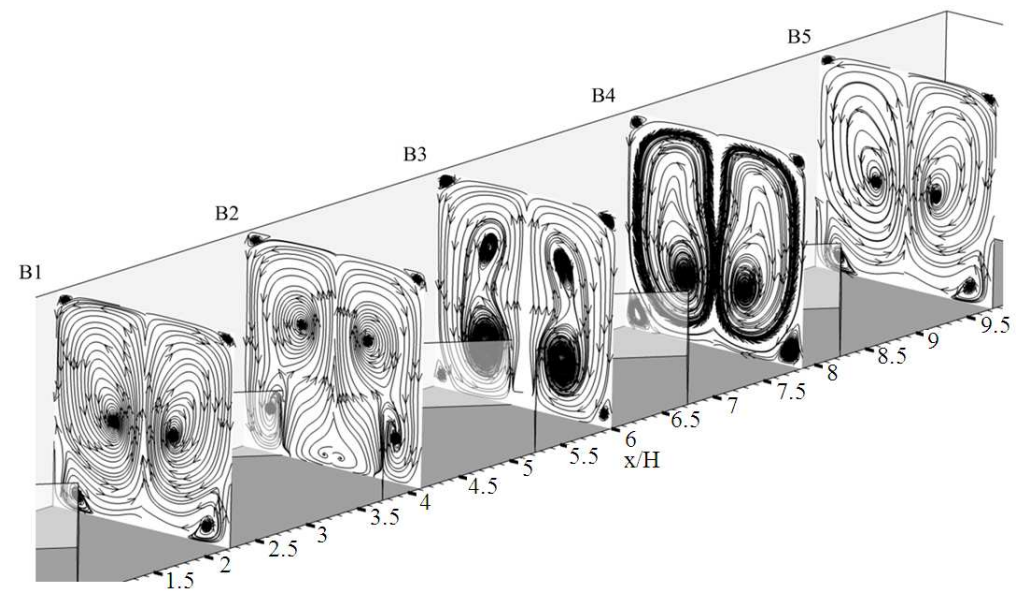

(b)

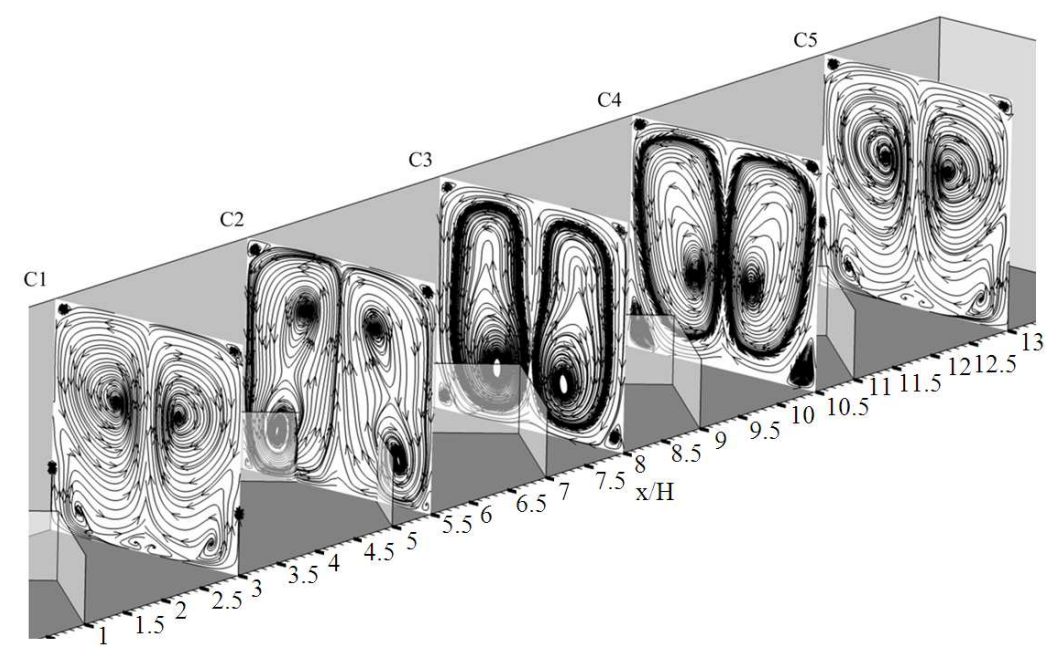

(c)

Fig. 3. Streamlines in transverse planes for (a) $P R=1$, (b) $P R=1.5$ and (c) $P R=2$ at $R e=1000$ and $B R=0.3$ 


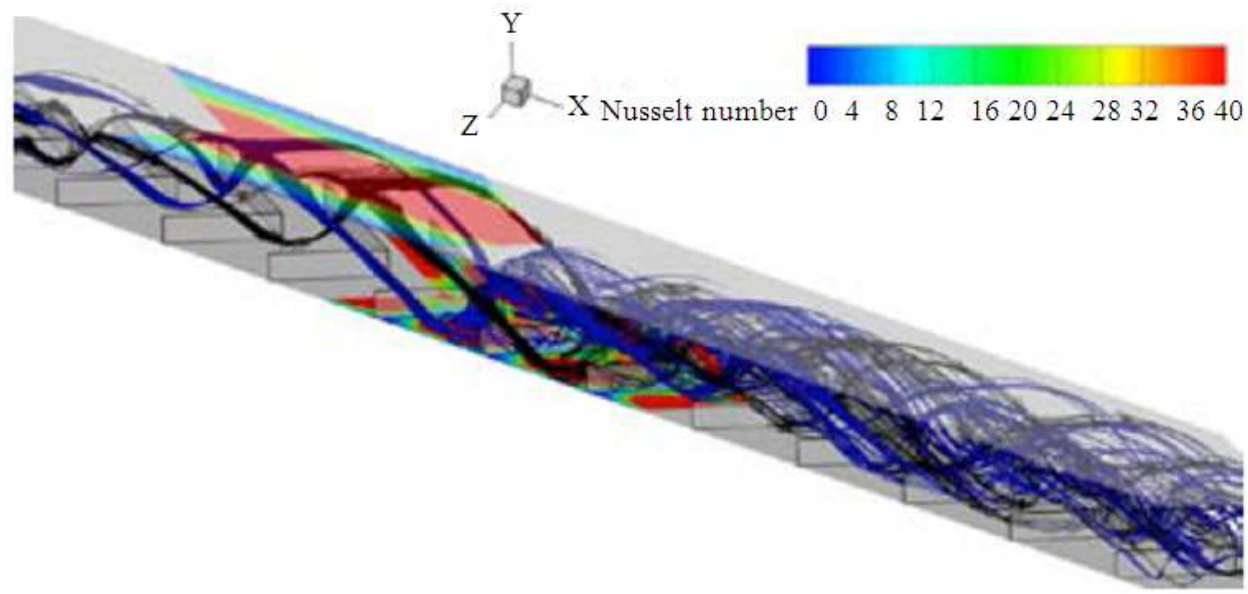

(a)

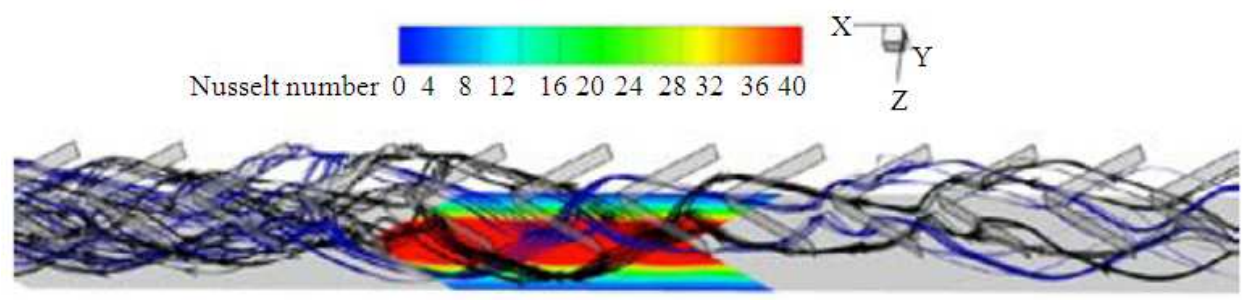

(b)

Fig. 4. Streamlines of impinging jet of cells on (a) lower and (b) upper walls at $\mathrm{Re}=1000, \mathrm{PR}=1$ and $\mathrm{BR}=0.3$

It is visible in Fig. 3 that there are two main vortices flows (or vortex core) in the $\mathrm{V}$-baffled channel, four small vortices at the channel corners. A single module considered herein begins at the Baffle Leading Edge (BLE) to the BLE of the next module. By considering two counter-rotating vortices of the module with $\mathrm{PR}=1$, before the fluid flow passes the baffle, two centers of the main counter-rotating vortex flows (common-vortex flow-up) at the BLE plane, plane A1 in Fig. 3a, are near the central area at about the baffle tip level while two small vortices appear in the lower corners. When moving to the quarter module pitch location, plane A2, two vortex centers appearing up-stream of the baffle spirally moves up to the central region of the channel. The two small lower corner vortexes move close together to the middle area of the lower wall while two new small vortices appear at the lower corners downstream of the baffle. The two upstream main vortex cores seem to be vanishing while two downstream ones including the two small corner vortices are appearing at the half module pitch location as can be seen in plane A3. At the threequarter pitch location, plane A4, both the two upstream small and main vortex centers completely vanish while the two downstream small and main ones become larger and make a helical move closer together until passing the baffle $\mathrm{V}$-apex. The two vortex core centers repeat itself when getting to the BLE of the next downstream module, plane A5. This vortex flow pattern is also similar to the cases of $\mathrm{PR}=1.5$, planes B1-B5 in Fig. 3b and of $\mathrm{PR}=$ 2, planes C1-C5 in Fig. 3c, except for the two vortex core centers appearing at different locations.

The plots of streamlines and channel wall heat fluxes showing the impingement jets on the lower and upper walls of the modules at $\mathrm{PR}=1, \mathrm{BR}=0.3$ and $\mathrm{Re}=1000$ for the V-baffled channel by connecting several modules in the series are portrayed in Fig. $4 \mathbf{a}$ and b, respectively. In the figure, it can be observed that impinging jets occur repeatedly in a lower wall region of the inter-baffle cavity and in a large region on the upper wall. A close examination reveals that two helical vortex flows from both sides move along the baffle cavity to come close together at the V-tip area before rolling up to impinge on the upper wall and then move across 3-5 modules to impinge again on the lower wall of the modules downstream, depending on Re, PR and BR values. After impingement, the jet splits over the wall and recombines to become two helical streams (P-vortex) at the nearby baffles: 


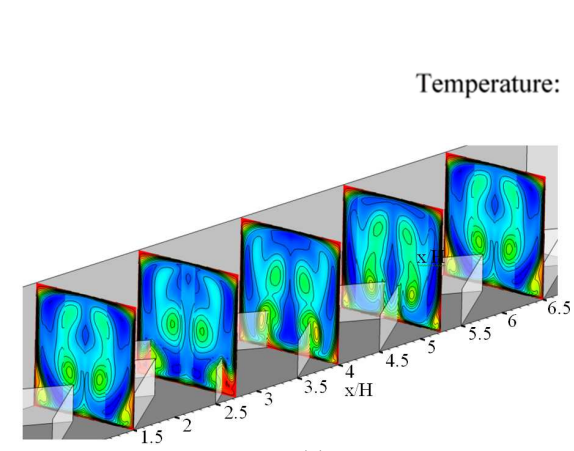

(a)

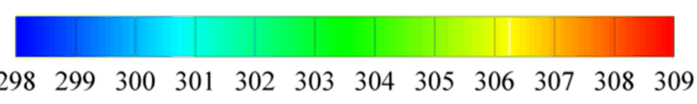

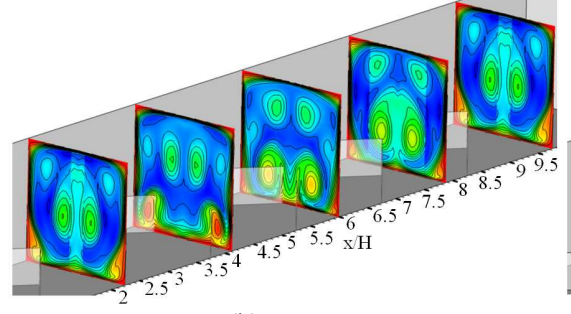

(b)

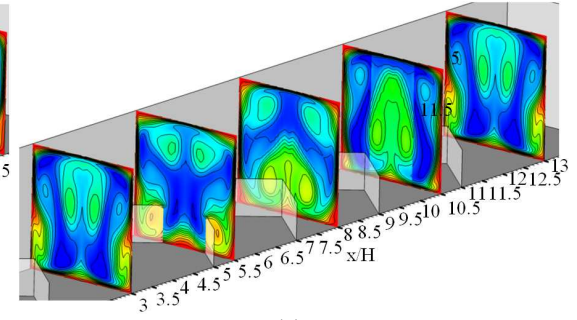

(c)

Fig. 5. Temperature contours in transverse planes for (a) $P R=1$, (b) $P R=1.5$ and (c) $P R=2$, at $R e=1000$ and $B R=0.3$

One stream joining at the upstream baffle and the other joining at the downstream baffle to create vortex filaments again with shorter pitch lengths. The helical pitch length of the main vortex flow is about $3 \mathrm{H}-5 \mathrm{H}$ before impingement and becomes shorter after impingement.

This means that the two helical vortex flows move along the baffle cavity and rolling up near the $\mathrm{V}$-apex area to pass over three to five baffle modules into the sidewall area before curling down to move along the baffle cavity again to complete the helical flow. If the helical vortex flow strength is sufficiently strong after 3 to 5 helixes, the helical flow becomes impingement flow.

\subsection{Temperature Field}

Figure 5a, b and c displays the contour plots of temperature field in transverse planes for the $\mathrm{BR}=0.3$ $\mathrm{V}$-baffle with (a) $\mathrm{PR}=1$, (b) $\mathrm{PR}=1.5$ and (c) $\mathrm{PR}=2$ at $\mathrm{Re}=1000$, respectively. In the figure, it is visible that there is a major change in the temperature field throughout the baffled channel. This indicates that the P-vortex flow provides a significant influence on the temperature 3.3 Temperature field Fig. 5a, b and c displays the contour plots of temperature field in transverse planes for the $\mathrm{BR}=0.3 \mathrm{~V}$-baffle with (a) $\mathrm{PR}=1$, (b) $\mathrm{PR}=1.5$ and (c) $P R=2$ at $R e=1000$, respectively. In the figure, it is visible that there is a major change in the temperature field through-out the baffled channel. This indicates that the P-vortex flow provides a significant influence on the temperature field, because it can induce better fluid mixing by trans-porting fluid from the central core to the near wall regions, leading to a high temperature gradient over the heated channel wall. The higher temperature gradient can be observed where the flow impinges the channel walls while the lower one is seen at the corner region and at the area behind the baffle where the temperature in those regions is somewhat high indicating that low temperature gradient occurs. However, the temperature fields for all the three cases are seen to be similar and almost distributed uniformly in the entire flow indicating excellent mixing of the fluid flow.

\subsection{Local and Average Nusselt Number}

Local $\mathrm{Nu}_{\mathrm{x}}$ contours for the $30^{\circ} \mathrm{V}$-shaped baffles with (a) $\mathrm{PR}=1$, (b) $\mathrm{PR}=1.5$ and (c) $\mathrm{PR}=2$ at $\mathrm{Re}=$ $1000, \mathrm{BR}=0.3$ are shown in Fig. 6a, $\mathbf{b}$ and $\mathbf{c}$, respectively. In the figure, it is apparent that the higher $\mathrm{Nu}_{\mathrm{x}}$ values over the walls are seen to be in a larger area, especially in the central area of the upper wall. The lower $\mathrm{Nu}_{\mathrm{x}}$ can be ob-served at the corner regions and the area around the baf-fle. The peak values are found at the impingement areas on the upper wall and on the inter-baffle cavity. The peak $\mathrm{Nu}_{\mathrm{x}}$ values for the $\mathrm{V}$-baffle are found to be about 14.5 times higher than those for the smooth channel. This indicates a merit of employing the V-baffle over the smooth square channel for enhancing heat transfer.

The variation of the average $\mathrm{Nu} / \mathrm{Nu}_{0}$ ratio with $\mathrm{Re}$ values for the V-baffles at various PRs and BRs is depicted in Fig. 7. In the figure, it is noted that the $\mathrm{Nu} / \mathrm{Nu}_{0}$ value tends to increase with the rise of $\mathrm{BR}$ and Re values while shows an opposite trend with the increase in PR. The maximum $\mathrm{Nu} / \mathrm{Nu}_{0}$ values for $\mathrm{PR}=1$, 1.5 and 2 are around $14.49,14.40$ and 13.63 at $\mathrm{BR}=0.5$, $\mathrm{Re}=1200$, respectively. The scrutiny of Fig. 7 reveals that the V-baffle yields the heat transfer rate of about 1.00-14.49 times over the channel with no baffle, depending on the BR, PR and Re values.

\subsection{Pressure loss}

The variation of the friction factor ratio, $f / f_{0}$ with $R e$ values at various BRs and PRs is displayed in Fig. 8. 


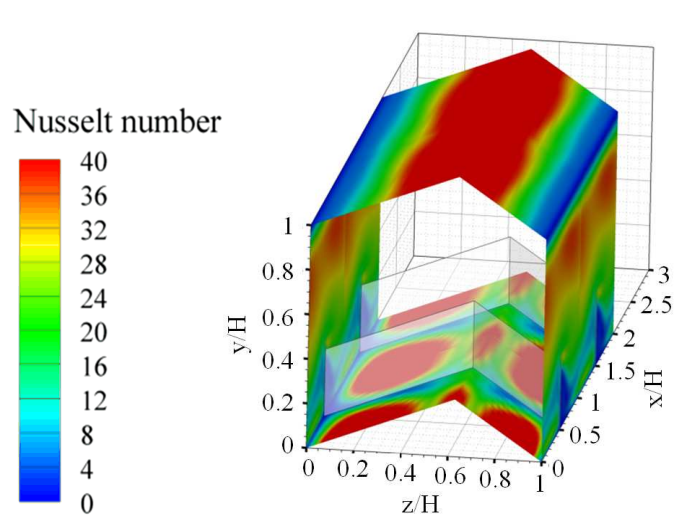

(a)

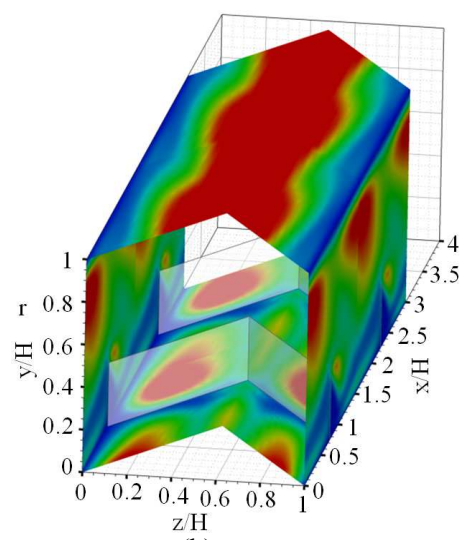

(b)

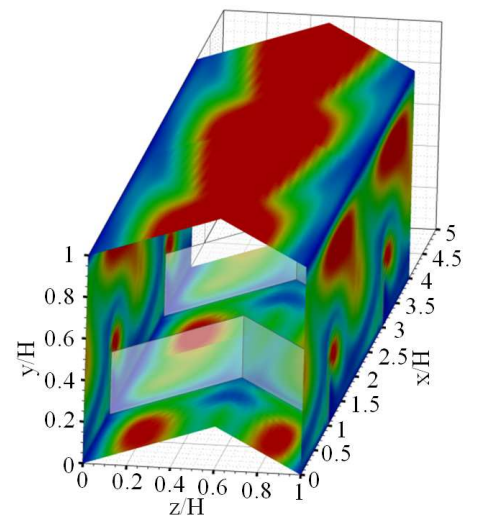

(c)

Fig. 6. $\mathrm{Nu}_{\mathrm{x}}$ Contours for (a) $\mathrm{PR}=1$, (b) $\mathrm{PR}=1.5$ and (c) $\mathrm{PR}=2$ at $\mathrm{Re}=1000$ and $\mathrm{BR}=0.3$

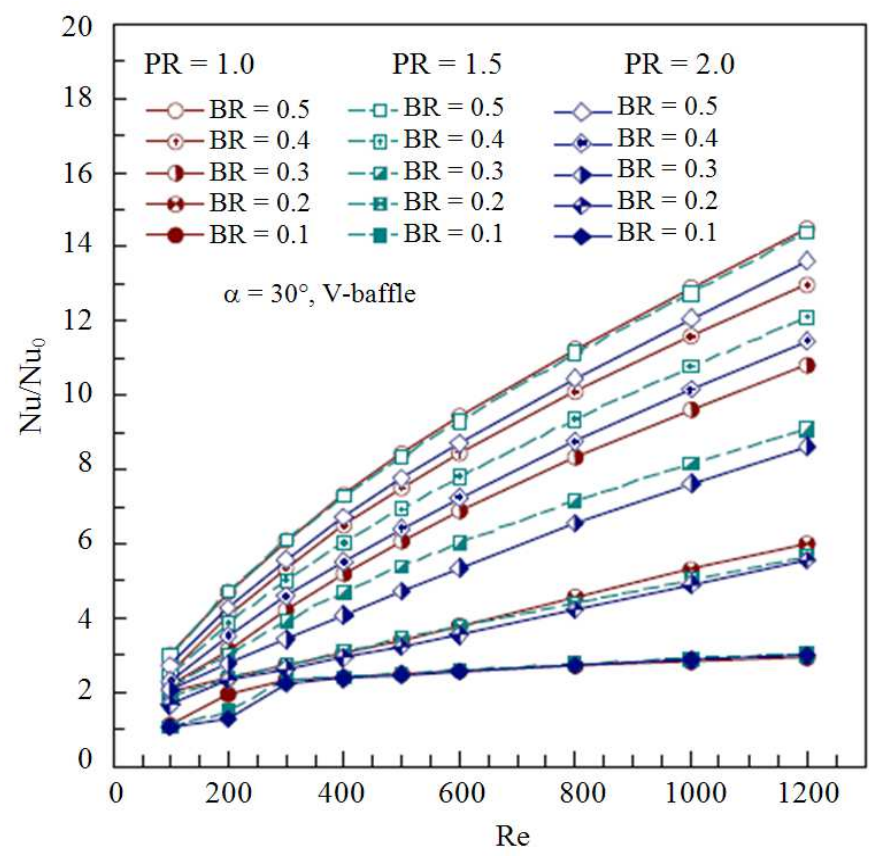

Fig. 7. Variation of $\mathrm{Nu} / \mathrm{Nu}_{0}$ with Reynolds number for various $\mathrm{BRs}$ and PRs

In the figure, it is obvious that the $\mathrm{f} / \mathrm{f}_{0}$ value tends to increase with the increment of $\mathrm{Re}$ and $\mathrm{BR}$ values but to decrease with increasing $\mathrm{PR}$ values. The $\mathrm{PR}=1$ baffle case provides the highest $\mathrm{f} / \mathrm{f}_{0}$ value while the $\mathrm{PR}$ $=2$ baffle yields the lowest for similar BRs. The friction factor for the V-baffles appear to be about 2.2-313.3 times higher than that for the channel with no baffle. Thus the flow blockage due to the presence of the baffles is a vital factor to cause a high pressure drop. Effect of $P R$ values on the $f / f_{0}$ value is also depicted in Fig. 8. It is worth noting that the use of higher PR value leads to a considerable reduction of friction factor.

\subsection{Performance Evaluation}

Figure 9 shows the variation of Thermal Enhancement Factor (TEF) for air flowing in the Vbaffled square channel. In the figure, the TEF of the Vbaffle tends to increase with the rise of $\mathrm{Re}$ and $\mathrm{BR}$ values whereas shows a uniform trend for $\mathrm{BR}=0.1$ at $\mathrm{Re}>300$. 
Amnart Boonloi and Withada Jedsadaratanachai / American Journal of Applied Sciences 10 (10): 1287-1297, 2013

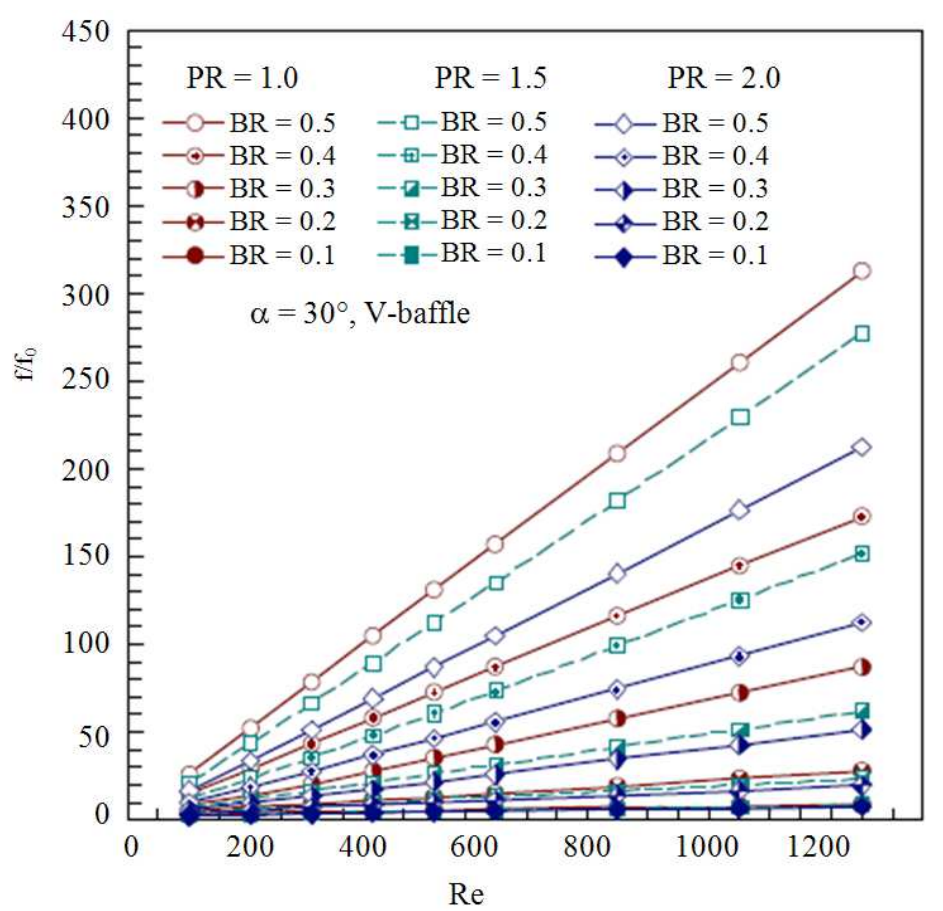

Fig. 8. Variation of $\mathrm{f} / \mathrm{f}_{0}$ with Reynolds number at various BRs and PRs

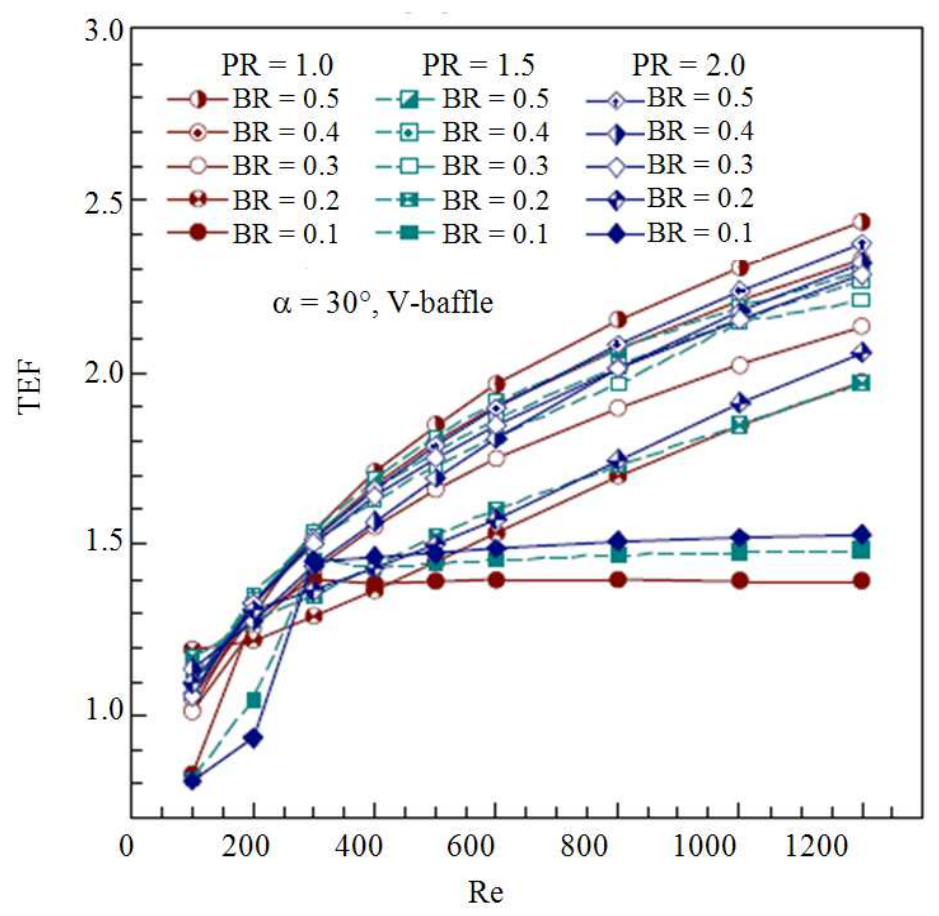

Fig. 9. Comparison of TEF at various BRs and PRs 
Amnart Boonloi and Withada Jedsadaratanachai / American Journal of Applied Sciences 10 (10): 1287-1297, 2013

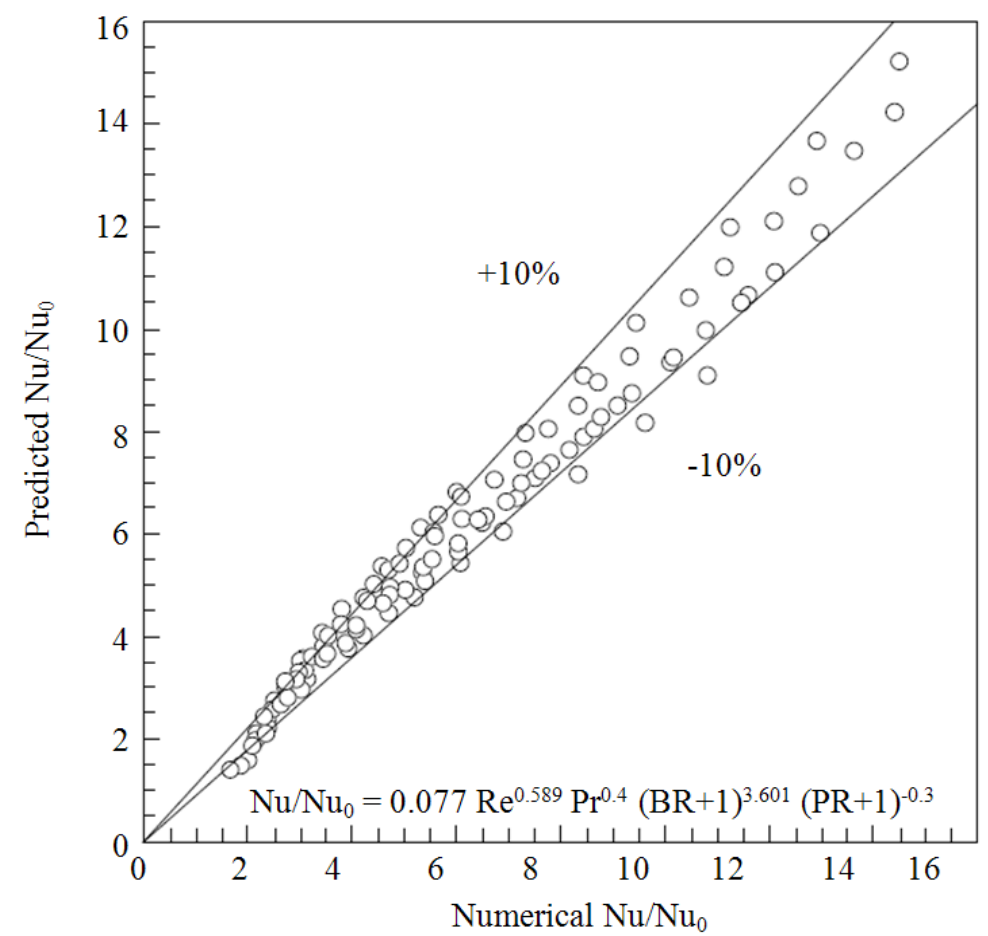

(a)

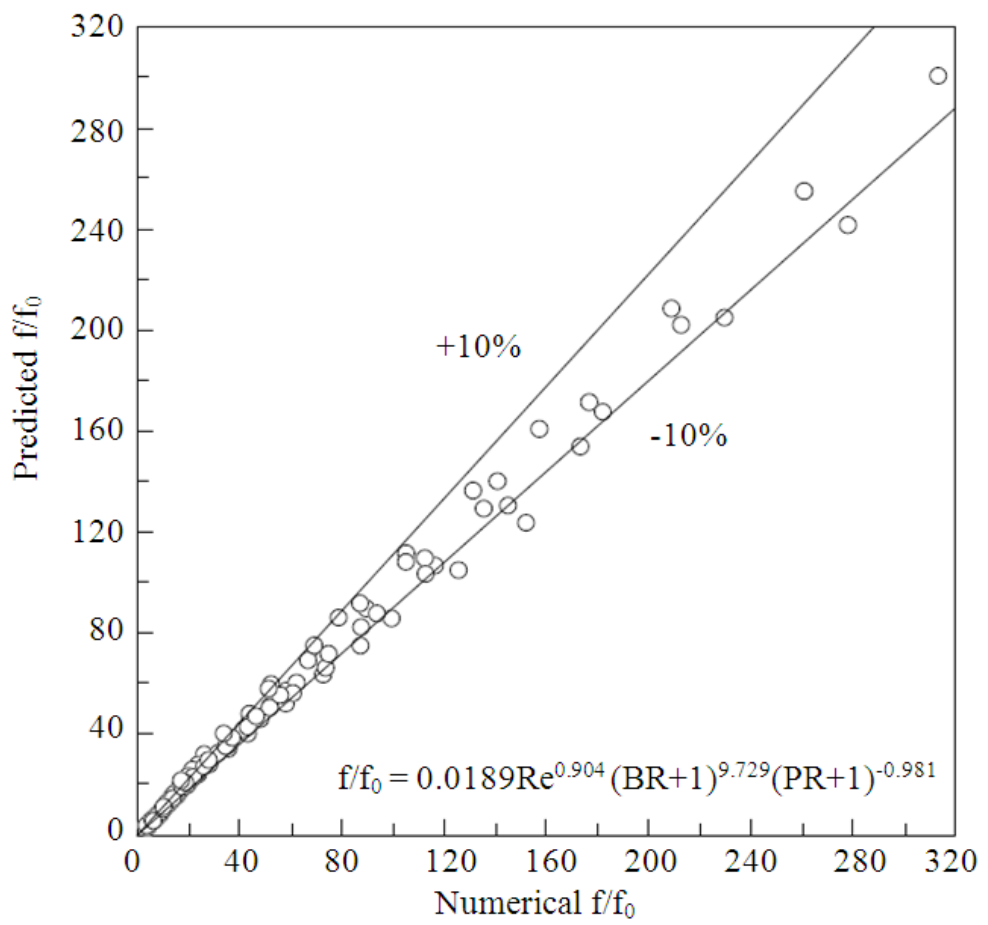

(b)

Fig. 10. Comparison of (a) $\mathrm{Nu} / \mathrm{Nu}_{0}$ and (b) $\mathrm{f} / \mathrm{f}_{0}$ obtained from the present correlations with numerical data 
The highest TEF for the V-baffle with $\mathrm{PR}=1$ and 1.5 is found at $\mathrm{BR}=0.3$ while that with $\mathrm{PR}=2$ is at $\mathrm{BR}=0.4$. The TEF values of all the V-baffle cases are seen to be above unity except for $\mathrm{BR}=0.1, \mathrm{Re} \leq 200$ and vary between 0.80 and 2.44 , depending on the BR, PR and Re values. It is interesting to note that at $\mathrm{Re}=1200$, the maximum TEF values for the V-baffle with $\mathrm{PR}=1,2$ and 1.5 are, respectively, 2.44, 2.37 and 2.29 at $\mathrm{BR}=$ $0.3,0.4$ and 0.3 .

The Nusselt number and friction factor values obtained from using the $30^{\circ} \mathrm{V}$-baffle are correlated as below:

$$
\begin{aligned}
& \mathrm{Nu} / \mathrm{Nu}_{0}=0.077 \operatorname{Re}^{0.579} \operatorname{Pr}^{0.4}(\mathrm{BR}+1)^{3.601}(\mathrm{PR}+1)^{-0.3} \\
& \mathrm{f} / \mathrm{f}_{0}=0.0189 \mathrm{Re}^{-0.904}(\mathrm{BR}+1)^{9.729}(\mathrm{PR}+1)^{-0.981}
\end{aligned}
$$

Comparisons of the $\mathrm{Nu} / \mathrm{Nu}_{0}$ and the $\mathrm{f} / \mathrm{f}_{0}$ obtained from the present prediction with those from the above correlations, Equation 10 and 11 are depicted in Fig. 10a and $\mathbf{b}$, respectively. In the figure, the majority of the predicted data falls within $\pm 10 \%$ for the present correlations for both $\mathrm{Nu} / \mathrm{Nu}_{0}$ and $\mathrm{f} / \mathrm{f}_{0}$.

\section{CONCLUSION}

Numerical computations of laminar periodic flow and heat transfer characteristics in a square channel fitted with $30^{\circ} \mathrm{V}$-baffle elements in tandem on the lower wall only are performed. The P-vortex flow created by the Vbaffle exists and helps to induce impingement flows over the channel walls leading to a drastic increase in heat transfer in the channel. The order of heat transfer enhancement is about 1.00-14.49 times for using the Vbaffle with $\mathrm{BR}=0.1-0.5$ and $\mathrm{PR}=1,1.5$ and 2 . However, the heat transfer augmentation is associated with enlarged pressure loss ranging from 2.18 to 313.24 times above the smooth channel depending on the BR, $\mathrm{PR}$ and $\mathrm{Re}$ values. It is found that the optimum TEF value in the present investigation is about 2.44 for $\mathrm{V}$ baffle with $\mathrm{BR}=0.3, \mathrm{PR}=1$ at $\mathrm{Re}=1200$.

\section{ACKNOWLEDGEMENT}

This research was funded by College of Industrial Technology, King Mongkut's University of Technology North Bangkok, Thailand.

The author would like to thank Assoc.Prof.Dr Pongjet Promvonge and Dr. Withada Jedsadaratanachai, KMITL for suggestions.

\section{REFERENCES}

Incropera, F., P.D. Dewitt, T.L. Bergman and A.S. Lavine, 2007. Introduction to Heat Transfer. 6th Edn., John Wiley and Sons Inc., ISBN-10: 0471794716.

Karwa, R. and G. Chitoshiya, 2013. Performance study of solar air heater having $\mathrm{v}$-down discrete ribs on absorber plate. Energy, 55: 939-955. DOI: 10.1016/j.energy.2013.03.068

Peng, W., P.X. Jiang, Y.P. Wang and B.Y. Wei, 2011. Experimental and numerical investigation of convection heat transfer in channels with different types of ribs. Applied Thermal Eng., 31: 2702-2708. DOI: 10.1016/j.applthermaleng.2011.04.040

Promvonge, P. and S. Kwankaomeng, 2010. Periodic laminar flow and heat transfer in a channel with $45^{\circ}$ staggered V-baffles. Int. Commun. Heat Mass Transfer, 37: 841-849. DOI: 10.1016/j.icheatmasstransfer.2010.04.002

Promvonge, P., S. Skullong, S. Kwankaomeng and C. Thiangpong, 2012a. Heat transfer in square duct fitted diagonally with angle-finned tape-Part 2: Numerical study. Int. Commun. Heat Mass Transfer. 39: 625-633. DOI: 10.1016/j.icheatmasstransfer.2012.03.010

Promvonge, P., S. Sripattanapipat and S. Kwankaomeng, 2010a. Laminar periodic flow and heat transfer in square channel with $45^{\circ}$ inline baffles on two opposite walls. Int. J. Thermal Sci., 49: 963-975. DOI: 10.1016/j.ijthermalsci.2010.01.005

Promvonge, P., W. Jedsadaratanachai and S. KwankaoMeng, 2010b. Numerical study of laminar flow and heat transfer in square channel with $30^{\circ}$ inline angled baffle turbulators. Applied Thermal Eng., 30: 1292-1303.

DOI: 10.1016/j.applthermaleng.2010.02.014

Promvonge, P., W. Jedsadaratanachai, S. Kwankaomeng and C. Thianpong, 2012b. 3D simulation of laminar flow and heat transfer in V-baffled square channel. Int. Commun. Heat Mass Transfer, 39: 85-93. DOI: 10.1016/j.icheatmasstransfer.2011.09.004

Sriromreun, P., C. Thianpong, P. Promvonge, 2012. Experimental and numerical study on heat transfer enhancement in a channel with Z-shaped baffles. Int. Commun. Heat Mass Transfer. 39: 945-952. DOI: 10.1016/j.icheatmasstransfer.2012.05.016

Versteeg, H.K. and W. Malalasekera, 2007. An Introduction to Computation Fluid Dynamics. 2nd Edn., Pearson Education, ISBN-10: 9780131274983. 